\section{THIRD-GENERATION SYPHILIS}

BY

\section{A. ELLIOTT, M.D., D.P.H}

MEDICAL OFFICER IN CHARGE OF VENEREAL DISEASE DEPARTMENT, ESSEX COUNTY HOSPITAL, COLCHESTER

The possibility of syphilis being transmitted to the third generation was, according to Cornaz, ${ }^{1}$ first described by Van Helmont in the seventeenth century. Fournier ${ }^{2}$ in 1891 was, however, the first modern syphilologist to draw serious attention to the condition, and although he considered it of infrequent occurrence he reported a large number of cases. Since that time the literature on the subject has grown mainly by contributions from abroad, the French being the chief workers in this field. With the exception of Nabarro, syphilologists in this country have given little attention to the condition. Nabarro ${ }^{3}$ 4 has collected thirty-one cases where the family history is available for three generations. In sixteen of these there was undoubted syphilis in the three generations, and in six syphilis was probably present. In the remaining seven it was possibly present. $\mathrm{He}$ adds to the first group two cases where both parents suffered from congenital syphilis. The evidence presented is in accord with modern standards of diagnosis. In this there is a sharp distinction from many cases reported by foreign writers, which fail to satisfy critical investigation, and where the diagnosis of syphilis in the third generation is made on slender clinical evidence.

\section{Diagnostic Criteria}

For the diagnosis of third-generation syphilis Sams ${ }^{5}$ has given the following criteria.

1. The diagnosis of syphilis in the third generation should be based upon a specific lesion, definite stigmata, or a repeatedly positive blood test.

2. Acquired syphilis in one of the grandparents (first generation), preferably the grandmother, must be established.

3. Congenital syphilis in one of the parents (second generation), and again preferably the mother.

4. Exclusion of acquired syphilis in both parents and children so far as is possible.

5. Certainty of parentage of the children in question.

Sams states that rigid adherence to these criteria makes it impossible to present a case which is beyond question, for it is obvious that the exclusion of acquired syphilis in the second generation can never be absolute. Nevertheless, he considers that reasonable satisfaction of the postulates given may be accepted as constituting proof of third-generation disease, and on these grounds the following case is deemed worthy of record.

\section{Case Records}

The X. family were first investigated in May, 1934, by Dr. Hamilton Wilkie of Leicester, and I am greatly indebted to him for the details of his findings, which were as follows.

First Generation.-Father, aged 55, had strongly positive Wassermann and Kahn blood reactions, but showed no clinical signs of active syphilis. Mother, aged 56, had strongly positive Wassermann and Kahn blood reactions, and clinically showed signs of early general paralysis.

Second Generation.-The children of these parents were: Daughter, aged 32, who showed no serological evidence of syphilis. Daughter (Mrs. Z.), aged 27, who had strongly positive Wassermann and Kahn blood reactions, but presented no clinical signs of active syphilis. Son, aged 25, who showed no serological evidence of syphilis. Son, aged 23 who had strongly positive Wassermann and Kahn reactions. This man was found to be suffering from interstitial keratitis, and was the cause for the investigation of the remainder of the family. Son, aged 21, who presented no serological evidence of syphilis.

At the time of the investigation the daughter, Mrs. Z., was on holiday in Leicester, and was referred to the Colchester Clinic for treatment, commencing on May 13th, 1934. She attended regularly until February 1st, 1935, and during this period of treatment received the following injections: seven of N.A.B. (2.55 grams), eleven of stabilarsan (3.3 grams), and ten of bismostab (1.2 grams). The Wassermann reaction remained strongly positive during this period. In June, 1934, she became pregnant for the first time, and in March, 1935 , was delivered of a living female child; a sample of placental blood taken by the practitioner in attendance at the delivery gave a positive Wassermann reaction $(++)$.

The child, representing the third generation of the $X$. family, was brought to the Coichester Clinic when 6 weeks old. It was apparently healthy, but showed positive $(++)$ Wassermann and Kahn blood reactions, findings which were repeated in a specimen taken a week later. Treatment was commenced for the mother and child, in the case of the latter with 0.005 gram kharsulphan weekly. As this drug was well tolerated, the dosage was gradually increased to the present one of 0.15 gram. Over the past six months twentytwo injections of kharsulphan have been given, a total amount of 1.18 grams ; and on November 6th, 1935, the Wassermann and Kahn reactions were negative. On this date the serological reactions of the mother were still strongly positive.

The father of this child has a negative Wassermann reaction, and there is no evidence of his having had acquired syphilis.

Reviewing this family in the light of Sams's criteria it will be seen that the diagnosis in the case of the third generation is established by the two positive blood tests. There is definite evidence of syphilis in the grandparents, but the evidence of congenital syphilis in the second generation is not so clearly established. It depends on the presence of interstitial keratitis in one son and the findings in the case of the daughter, Mrs. $Z$.

It is possible for interstitial keratitis to occur in cases of acquired syphilis, but such cases are extremely rare. Carpenter $^{6}$ had three such in 19,000 cases of acquired syphilis, while Stokes $^{7}$ states he has never seen one, although he does not deny its existence. In the instance given I consider that as there is such definite evidence of syphilis in the first generation it is reasonable to affirm that the interstitial keratitis occurring in the second generation is a definite manifestation of congenital syphilis. In the case of the daughter, Mrs. Z., the persistently positive Wassermann reaction in spite of seventeen months' treatment points to a diagnosis of congenital syphilis. This contention is supported by her family history, the absence of miscarriages and stillbirths, and her husband's freedom from the infection. The final postulate laid down by Sams is satisfied in this case, as there is no doubt as to the parentage of the child of the third generation.

This case is therefore presented as one of third-generation syphilis.

I wish to express my thanks to Dr. W. A. Bullough, county medical officer for Essex, for permission to publish this case.

\section{References}

${ }^{1}$ Cornaz: Rev. Méd. de la Suisse Rom., 1926, xlvi, 220.

${ }^{2}$ Fournier: L'Hérédité Syphilitique, Paris, 1891

3 Nabarro: Brit. Journ. Ven. Dis., IX, 1

Idem: Acta Paediatrica, 1933, xvi, 498

Sams: Amer. Journ. Syph., 1933, xvii, 492

- Carpenter: Ann. Ophthalmol., 1908, xvii, 617.

'Stokes: Modern Clinical Sy'philology, 1926.

Dr. Anthony Bassler has been elected president of the United States Society for the Advancement of Gastroenterology, president of the American Committee and United States Delegate to the International Society of Gastro-enterology, and an honorary member of the Belgian Gastro-enterological Society. 